\title{
CORRELATION OF MENSTRUAL DISORDERS AND THYROID DISEASES AMONG REPRODUCTIVE AGE GROUP WOMEN IN A TERTIARY CARE CENTRE, KIMSDU, KARAD
}

\author{
Manisha M. Laddad' , N. S. Khirsagar², Sanjaykumar Patil3, Gauri Shinde4 \\ ${ }_{1}^{1}$ Associate Professor, Department of Obstetrics and Gynaecology, KIMS, Karad. \\ 2 Professor, Department of Obstetrics and Gynaecology, KIMS, Karad. \\ ${ }^{3}$ Professor, Department of Obstetrics and Gynaecology, KIMS, Karad. \\ ${ }^{4}$ Assistant Professor, Department of Obstetrics and Gynaecology, KIMS, Karad.
}

\section{ABSTRACT}

\section{OBJECTIVE}

To study the prevalence of thyroid disorders and its correlation with menstrual disorders.

\section{METHODS}

200 women aged between 15 and 45 years who attended Gynaecology OPD in Krishna Institute of Medical Sciences, Deemed University, Karad, were included for this cross-sectional study. The study group comprised 100 patients presenting with menstrual complaints. The control group consisted of 100 women of same age group with complaints other than menstrual disorders. Thyroid function tests, anti-TPO antibody estimation, and endometrial sampling were done in all patients.

\section{RESULTS}

In patients with menstrual disorders and Abnormal Uterine Bleeding, 40\% had thyroid disorders in which subclinical hypothyroidism was prevalent in $22 \%$, overt hypothyroidism in $14 \%$, and overt hyperthyroidism in $5 \%$ of the women. Autoimmune thyroid antibodies were present in $40 \%$ patients of women with menstrual disorders and Abnormal Uterine Bleeding. On endometrial sampling, hypothyroid patients mainly had proliferative endometrial $(42.85 \%)$ whereas hyperthyroid had atrophic endometrium $(60 \%)$.

\section{CONCLUSIONS}

Thyroid dysfunction is an important causative aetiology of Abnormal Uterine Bleeding and menstrual disorders. Assessment of thyroid function should be done in all patients with Abnormal Uterine Bleeding and menstrual disorders to avoid unnecessary interventions like Dilatation \& Curettage and hysterectomy.

\section{KEYWORDS}

Thyroid Disorders, Menstrual Disorders, Abnormal Uterine Bleeding, Subclinical Hypothyroidism, Thyroid Autoimmunity.

HOW TO CITE THIS ARTICLE: Laddad MM, Khirsagar NS, Patil S, et al. Correlation of menstrual disorders and thyroid diseases among reproductive age group women in a tertiary care centre, KIMSDU, Karad. J. Evolution Med. Dent. Sci. 2016;5(76):5661-5664, DOI: $10.14260 /$ jemds/2016/1277

\section{INTRODUCTION}

The prevalence of hypothyroidism in women in the reproductive age (15 to 45 years) varies between $2 \%$ and $4 \% .^{[1]}$ In this age group, autoimmune thyroid disease (AITD) is the most common cause of hypothyroidism. ${ }^{[2]}$ Hypothyroidism is associated with a broad spectrum of reproductive disorders ranging from abnormal sexual development through menstrual irregularities to infertility.

Menstrual disorders pose a huge burden on Gynaecology OPD, accounting for approximately $20 \%$ of attendance.[1,2] Thyroid hormones play an important role in normal reproductive physiology through direct effects on the ovaries and indirectly by interacting with sex hormone-binding globulin. Thyroid dysfunction can lead to menstrual irregularities and infertility.[2,3] In India, thyroid disorders are among the most common endocrine diseases.[3]

Financial or Other, Competing Interest: None.

Submission 17-08-2016, Peer Review 10-09-2016,

Acceptance 16-09-2016, Published 22-09-2016.

Corresponding Author:

Dr. Manisha M. Laddad

\#75/A Block, Vithal Dev Housing Society,

Malkapur, Karad-415110

E-mail: drmanishald@gmail.com

DOI: $10.14260 /$ jemds $/ 2016 / 1277$
Onset of thyroid disorders increases with age, and it is estimated that $29 \%$ of premenopausal and menopausal women are diagnosed with thyroid disease. ${ }^{[4]}$ Thyroid disorders are more common in women than in men and in older adults compared with younger age groups.[5]

Hypothyroidism is associated with a wide spectrum of reproductive disorders ranging from abnormal sexual development, menstrual irregularities, AUB and infertility.[6] The impact of hypothyroidism on the menstrual cycle has been identified since the 1950s and leads to changes in cycle length and blood flow.[6] Subclinical hypothyroidism has been associated with occult menorrhagia (Mild disturbances in menstrual amount and duration) before becoming symptomatic. ${ }^{[7]}$ The prevalence of subclinical hypothyroidism is as high as $11.5 \%$ in women. ${ }^{[8]}$

Hyperthyroidism occurring before puberty has been reported to delay the onset of menses.[9] In women of fertile age group, oligomenorrhoea and amenorrhoea are the commonest abnormalities associated with hyperthyroidism.[9] These irregularities sometimes precede thyroid dysfunction. In the present times, subclinical hyper- and hypothyroidism can be diagnosed very early, whereas these would have passed unnoticed a few decades ago. Timely detection of Thyroid disorder in patients presenting with menstrual disorders and their management can prevent surgical intervention like curettage and hysterectomy. 
Thyroid autoimmunity has been shown to have association with various kinds of thyroid dysfunction. Although there are foreign studies to relate the occurrence of thyroid dysfunction in women with menstrual disorders, but there are not many Indian studies in this regard.[10,11]

\section{OBJECTIVE}

To study the prevalence of thyroid dysfunction and thyroid autoimmunity in patients with menstrual disorders and to study their correlation with histopathology finding in reproductive age group.

\section{METHODS}

The present study was conducted in the Department of Obstetrics and Gynaecology, Krishna Institute of Medical Sciences, Karad, in the period of 12 months between March 2015 and March 2016. 200 women of reproductive age group 15-45 years were selected. Study group comprised 1000 women with menstrual disorders like AUB, menorrhagia, oligomenorrhoea, hypomenorrhoea, polymenorrhoea, metrorrhagia, and amenorrhoea and control group comprised women with complaints other than menstrual disorders. Patients with menstrual disorder having any known organic pathology like uterine fibroid, adenomyosis, tubercular endometriosis, polyp, uterine malignancy, etc. and patients with IUCD in utero were excluded from study.

After taking detailed history regarding age, parity, age of menarche, menstrual disorders and dysmenorrhoea, general physical examination along with pelvic examination was carried out in women with menstrual complaints. Routine investigation like $\mathrm{Hb}$, Platelet count, TLC, DLC, ESR, ABO-Rh, and thyroid profile that includes T3, T4, TSH, and anti-TPO antibody was performed in all patients. Direct quantitative determination of $\mathrm{T} 3, \mathrm{~T} 4$, and TSH by ELISA using human serum-based calibration was performed. The calibrators were calibrated using a reference preparation, which has been assayed against the WHO 2nd IRP 80/558. They were also subjected to special investigations which include Transabdominal scan, endometrial sampling and hysteroscopy (wherever indicated).

Patients were considered as euthyroid if the TSH, T3, and $\mathrm{T} 4$ were within normal range $(\mathrm{TSH}$ level $=0.35-5.50 \mu \mathrm{IU} / \mathrm{mL}$, free $\mathrm{T} 3$ level $=1.10-4.1 \mathrm{pg} / \mathrm{mL}$, and free $\mathrm{T} 4$ level $=0.6-2.0$ $\mathrm{ng} / \mathrm{mL}$ ); when TSH was high with T3 and T4 within normal range, they were labelled as subclinical hypothyroidism. Overt hypothyroidism was diagnosed with high TSH and low T3 and T4 levels, subclinical hyperthyroidism if the TSH was low and T3 and T4 levels were in normal range, and overt hyperthyroidism when TSH level was low and T3 and T4 levels were high.

Chi-square test and Fisher exact test have been used for qualitative data to calculate $\mathrm{p}$ value, and unpaired student $\mathrm{t}$ test and non-parametric Wilcox on-Mann-Whitney test were used to statistically compare quantitative data for T3, T4, TSH, and anti-TPO antibody values in between two groups. Difference with a $\mathrm{p}$ value of $<0.05$ was considered statistically significant.

\section{RESULTS}

The study and control groups were comparable in respect of age, religion, and socioeconomic status. Out of all the types of menstrual irregularities, 45 (45\%) presented with menorrhagia, 25 (25\%) had hypo/oligomenorrhoea, 18 (18\%) had polymenorrhoea, $10(10 \%)$ had metrorrhagia, and 2 (2\%) had amenorrhoea (Table 1).

$85 \%$ of women $(n=85)$ were found to be euthyroid in the control group, while in the study group $58 \%(n=58)$ patients were euthyroid and rest $42 \%(n=42)$ were associated with some or other forms of thyroid dysfunction.

\begin{tabular}{|c|c|c|}
\hline \multirow{2}{*}{$\begin{array}{l}\text { Presenting } \\
\text { Complaints }\end{array}$} & \multicolumn{2}{|c|}{ Study Group } \\
\hline & Number & $(\%)$ \\
\hline Amenorrhoea & 2 & 2 \\
\hline Hypo/Oligomenorrhoea & 25 & 25 \\
\hline Metrorrhagia & 10 & 10 \\
\hline Menorrhagia & 45 & 45 \\
\hline Polymenorrhoea & 18 & 18 \\
\hline Total & 100 & 100 \\
\hline
\end{tabular}

Thyroid dysfunctions were also found in $15 \%$ cases $(n=$ 15) of control group. Hypothyroidism was the commonest abnormality as seen in $36 \%$ cases in the study group, out of which $22 \%$ had subclinical hypothyroidism, while in the control group, hypothyroid was present in $12 \%$ patients. $06 \%$ of women in study group were hyperthyroid $(1 \%$ were subclinical hyperthyroid and 5\% were overt hyperthyroid), while it was $3 \%$ in control group. The difference was statistically significant $(\mathrm{p}$ value $=0.038$ i.e., $<0.05$ ) (Table 2).

Thyroid autoimmunity in the form of thyroid anti-TPO antibody was more prevalent in the study group (40\%) compared to control group (7\%). The difference is statistically significant with a p value of $0.005(<0.05)$ (Table 3$)$.

Among the patients with hypo/oligomenorrhoea, three cases $(12 \%)$ had subclinical hypothyroidism, four cases $(16 \%)$ had overt hypothyroidism, two cases $(08 \%)$ had subclinical hyperthyroidism, and four cases (16\%) had overt hyperthyroidism.

Among the patients with metrorrhagia, two cases (20\%) had subclinical hypothyroidism.

Among the patients with menorrhagia, eleven cases (24.44\%) had subclinical hypothyroidism and seven cases (15.55\%) had overt hypothyroidism.

Among the patients with polymenorrhoea, four cases $(22.22 \%)$ had subclinical hypothyroidism and three cases (16.60\%) had overt hypothyroidism.

This difference was statistically significant $(\mathrm{p}$ value $=0.028$, i.e., <0.05) (Table 4).

Among the patients with high TSH level, 42.85\% had proliferative endometrium, $28.50 \%$ had secretory endometrium, $21.50 \%$ had hyperplastic endometrium, and 7.15\% had atrophic endometrium.

Among the patients with low TSH level, $20 \%$ had proliferative and secretory endometrium each, and $60 \%$ had atrophic endometrium.

So, we can see that atrophic endometrium (60\%) is the commonest histopathological finding in women with hyperthyroidism and proliferative endometrium (42.85\%) with hypothyroidism.

This difference was statistically significant ( $\mathrm{p}$ value $=0.018$, i.e., $<0.05$ ) (Table 5).

\section{DISCUSSION}

Thyroid disorders in general and hypothyroidism in particular are the common causes of menstrual disorders in women. 
Menarche, pubertal growth and development, menstrual cycles, fertility and foetal development, post-partum period, reproductive years, and postmenopausal years are profoundly influenced by the thyroid status of women. It is recognised universally that menstrual disturbances may accompany and even may precede thyroid dysfunction.

Menorrhagia was the most common complaint among the patients with menstrual disorders, and most of the patients in other groups presented with white discharge in our study. Similar were observations of Pahwa $S$ et al[12] (48\%) and Padmaleela K et al[13] (54\%), where menorrhagia was the most common complaint.

In our study, the prevalence of hypothyroidism and hyperthyroidism in patients with menstrual disorders is almost two times higher than in the control population. In the study by Kaur T et al[14], out of 100 patients studied, 14 had hypothyroidism. In the study by Sharma $\mathrm{N},{ }^{[7]}$ prevalence of hypothyroidism was detected in $22 \%$ patients of DUB and hyperthyroidism in $14 \%$. In the study by Pahwa,[13] $22 \%$ cases of hypothyroidism and $76 \%$ of euthyroidism were reported, whereas Padmaleela ${ }^{[14]}$ observed thyroid disorders in $26.5 \%$ patients of DUB. The prevalence of hyperthyroidism was $8.4 \%$ among the DUB patients as assessed by the findings of their thyroid function tests. Gowri M. et al[15] found $17.6 \%$ women with hypothyroidism, $2.7 \%$ with subclinical hypothyroidism, and $4.7 \%$ with hyperthyroidism, which is similar to our study. In our study, the prevalence of anti-thyroid peroxidase antibodies in patients with menstrual disorders is almost four times higher than in the control population. This emphasises the significance of estimation of thyroid antibodies in patients with menstrual disorder. Different authors have used different methods for Anti-TPO antibody assay, and their results may vary with kits from different manufacturers. Our samples were evaluated for Anti-TPO Antibody using ELISA microwell kit (Xema Co., Ltd, Germany), with cut-off value $75 \mathrm{IU} / \mathrm{mL}$.

\begin{tabular}{|c|c|c|c|c|}
\hline \multirow{2}{*}{ Thyroid Status } & \multicolumn{2}{|c|}{ Study Group } & \multicolumn{2}{c|}{ Control Group } \\
\cline { 2 - 5 } & No. & $\mathbf{( \% )}$ & No. & $\mathbf{( \% )}$ \\
\hline Euthyroid & 58 & 58 & 85 & 85 \\
\hline Hypothyroid & & & & \\
\hline $\begin{array}{c}\text { Subclinical } \\
\text { hypothyroid }\end{array}$ & 22 & 22 & 9 & 9 \\
\hline Overt hypothyroid & 14 & 14 & 3 & 3 \\
\hline Hyperthyroid & & & & \\
\hline $\begin{array}{c}\text { Subclinical } \\
\text { hyperthyroid }\end{array}$ & 1 & 1 & 1 & 1 \\
\hline Overt 5 hyperthyroid & & 5 & 2 & 2 \\
\hline Total & $\mathbf{1 0 0}$ & $\mathbf{1 0 0}$ & $\mathbf{1 0 0}$ & $\mathbf{1 0 0}$ \\
\hline Table 2: Distribution
\end{tabular}

Table 2: Distribution of study and control group with respect to thyroid status

\begin{tabular}{|c|c|c|c|c|c|}
\hline \multirow{2}{*}{$\begin{array}{c}\text { Anti-TPO } \\
\text { Antibodies }\end{array}$} & $\begin{array}{c}\text { Study } \\
\text { Group }\end{array}$ & \multicolumn{3}{|c|}{$\begin{array}{c}\text { Control } \\
\text { Group }\end{array}$} & P Value \\
\cline { 2 - 6 } & No. & $\mathbf{( \% )}$ & No. & $\mathbf{( \% )}$ & \\
\hline Present & 40 & 40 & 7 & 7 & 0.005 \\
\hline Absent & 60 & 60 & 93 & 93 & \\
\hline Total & $\mathbf{1 0 0}$ & $\mathbf{1 0 0}$ & $\mathbf{1 0 0}$ & $\mathbf{1 0 0}$ & \\
\hline Table 3: Distribution of Study and Control Group with re \\
spect to anti-TPO Antibodies \\
\hline
\end{tabular}

\begin{tabular}{|c|c|c|c|c|c|}
\hline \multirow{2}{*}{$\begin{array}{l}\text { Menstrual } \\
\text { Disorders }\end{array}$} & \multirow[b]{2}{*}{ Euthyroid (\%) } & \multicolumn{2}{|c|}{ Hypothyroid } & \multicolumn{2}{|c|}{ Hyperthyroid } \\
\hline & & $\begin{array}{c}\text { Subclinical } \\
(\%)\end{array}$ & $\begin{array}{l}\text { Overt } \\
(\%)\end{array}$ & $\begin{array}{c}\text { Subclinical } \\
(\%)\end{array}$ & $\begin{array}{l}\text { Overt } \\
\text { (\%) }\end{array}$ \\
\hline Amenorrhoea $(\mathrm{N}=1)$ & $0(0)$ & $0(0)$ & $0(0)$ & $0(0)$ & $1(100)$ \\
\hline $\begin{array}{c}\text { Hypo/ Oligomenorrhoea } \\
(\mathrm{N}=25)\end{array}$ & $12(48)$ & $3(12)$ & $4(16)$ & $1(04)$ & $4(16)$ \\
\hline Metrorrhagia $(\mathrm{N}=10)$ & $58(80)$ & $2(20)$ & $0(0)$ & 0 & 0 \\
\hline Menorrhagia $(\mathrm{N}=45)$ & $27(60)$ & $11(24.44)$ & $7(15.56)$ & 0 & 0 \\
\hline Polymenorrhoea $(\mathrm{N}=18)$ & $11(61.11)$ & $4(22.22)$ & $3(16.66)$ & 0 & 0 \\
\hline Total N=100 & 58 & 22 & 14 & 1 & 5 \\
\hline
\end{tabular}

\begin{tabular}{|c|c|c|c|c|}
\hline \multirow{2}{*}{ TSH Level } & \multicolumn{4}{|c|}{ Histopathological Findings } \\
\cline { 2 - 5 } & $\begin{array}{c}\text { Proliferative } \\
(\%)\end{array}$ & $\begin{array}{c}\text { Secretory } \\
(\%)\end{array}$ & $\begin{array}{c}\text { Hyperplastic } \\
(\%)\end{array}$ & $\begin{array}{c}\text { Atrophic } \\
(\%)\end{array}$ \\
\hline Normal TSH (N = 50) (euthyroid) & $32(64)$ & $5(20)$ & $3(12)$ & $1(4)$ \\
\hline High TSH (N = 28) (hypothyroid) & $12(42.85)$ & $8(28.50)$ & $6(21.50)$ & $2(7.15)$ \\
\hline Low TSH (N = 10) (hyperthyroid) & $2(20)$ & $2(20)$ & $0(0)$ & $6(60)$ \\
\hline Total (N = 88) & $\mathbf{4 6}$ & $\mathbf{2 0}$ & $\mathbf{1 2}$ & $\mathbf{1 0}$ \\
\hline Table 5: Correlation of Histopathological Findings with TSH Level & \\
\hline
\end{tabular}

In the study group, we found proliferative endometrium in most of the patients on endometrial sampling followed by secretory endometrium in hypothyroid patients. In hyperthyroid patients, maximum number of patients had atrophic endometrium. In the study by Kaur and Sangeeta[14,16], 9 (64.3\%) hypothyroid patients had proliferative endometrium, $3(21.4 \%)$ had endometrial hyperplasia, and the rest $2(14.3 \%)$ had secretory endometrium. Sharma and Gowri[7,15] found $36.36 \%$ proliferative, $36.36 \%$ secretory and $27.27 \%$ atrophic endometrium in hypothyroid patients. In hyperthyroid patients, they found $42.84 \%$ proliferative, $28.56 \%$ secretory, and $14.28 \%$ hyperplastic endometrium on histopathology examination. In the study by Padmaleela, $[13]$ the most common finding in endometrial biopsy was proliferative endometrium (59.1\%), both in hypothyroid (60\%) and hyperthyroid cases (57.1\%). Cystic Glandular Hyperplasia was found only in 
$13.3 \%$ and secretory endometrium in $26.7 \%$ of the hypothyroid patients. Similar results in Ajmani et al study.

In our study, of total 36 hypothyroid patients, most of the patients had menorrhagia followed by polymenorrhoea, hypo/oligomenorrhoea, and metrorrhagia. Kaur[14] observed that among 28 hypothyroid patients, 18 (64.3\%) had menorrhagia, 6 (21.4\%) had oligomenorrhoea, and 4 (14.28\%) had metrorrhagia. Pahwa[14] found a total of 33 hypothyroid patients, in which 26 (78.94\%) had menorrhagia and $7(21.21 \%)$ had polymenorrhoea. In the study by Padmaleela[13], the commonest menstrual complaint was menorrhagia $(53.3 \%)$ followed by polymenorrhoea $(13.3 \%)$, and $20 \%$ had hypo/oligomenorrhoea in hypo-thyroid patients, which goes with our study. Among five hyperthyroid patients, the commonest complaint was hypo/ oligomenorrhoea followed by amenorrhoea. In the study by Kaur,[14] the patient with hyperthyroidism was found to have hypomenorrhoea. Pahwa[14] found that of two hyperthyroid patients, both had menorrhagia. In the study by Padmaleela and Ajmani,[14,16] among the hyperthyroid patients, $42.8 \%$ had menorrhagia, $28.6 \%$ had polymenorrhoea, and $14.3 \%$ had hypo/ oligomenorrhoea.

\section{CONCLUSIONS}

From our study, it may be concluded that there is a strong correlation of thyroid dysfunction with menstrual disorders. In the patients with menstrual dysfunction, if thyroid disorders are timely diagnosed and treated, the menstrual irregularities settle, and unnecessary intervention like hormonal treatment and surgery can be avoided. The menstrual abnormalities most commonly seen are menorrhagia followed by hypo/oligomenorrhoea and polymenorrhoea. Since thyroid dysfunction is an important treatable cause of menstrual disorder, estimation of thyroid status should be a part of the battery of investigations being done in the patients of menstrual disorders. The prevalence of subclinical hypothyroidism in patients with menstrual disorders emphasises the need to detect the hypothyroidism at this stage, so that treatment can be initiated and progression to overt disease be slowed down as a part of management of menstrual disorders.

The estimation of anti-TPO antibody is an expensive test. We recommend its testing as a routine test in the evaluation of patients with menstrual disorders. However, prospective studies are required to analyse the cost effectiveness of antiTPO antibody testing and its possible benefits with regard to treatment.

\section{ACKNOWLEDGEMENT}

We record our sincere thanks to our Medical Director, KIMSDU, Karad and head of our department for allowing us to use and publish the data related to patients.

\section{REFERENCES}

1. Albers JR, Hull SK, Wesley RM. Abnormal uterine bleeding. Am Fam Phys 2004;69(8):1915-26.

2. Poppe K, Glinoer D. Thyroid autoimmunity and hypothyroidism before and during pregnancy. Human Reprod Update 2003;9(2):149-61.

3. Kochupillai N. Clinical endocrinology in India. Curr Sci 2000;79(8):1061-7.

4. Hollowell JG, Staehling NW, Flanders WD, et al. Serum TSH, T4, and thyroid antibodies in the United States population (1988 to 1994): national health and nutrition examination survey (NHANES III). J Clin Endocrinol Metab 2002;87(2):489-99.

5. Cappola AR, Ladenson PW. Hypothyroidism and atherosclerosis. J Clin Endocrinol Metab 2003;88(6):243844.

6. Bals-Pratsch M, Geyter D, Muller C, et al. Episodic variations of prolactin, thyroid-stimulating hormone, luteinizing hormone, melatonin and cortisol in infertile women with subclinical hypothyroidism. Human Reprod 1997;12(5):896-904.

7. Sharma N, Sharma A. Thyroid profile in menstrual disorders. JK Science 2012;14(1):14-7.

8. Abraham R, Murugan VS, Pukazhvanthen P, et al. Thyroid disorders in women of Puducherry. Indian J Clin Biochem 2009;24(1):52-9.

9. Thomas R, Reid RL. Thyroid disease and reproductive dysfunction: a review. Obstet Gynecol 1987;70(5):789-98.

10. Koutras DA. Disturbances of menstruation in thyroid disease. Ann NY Acad Sci 1997;816:280-4.

11. Kakuno Y, Amino N, Kanoh M, et al. Menstrual disturbances in various thyroid diseases. Endocr J 2010;57(12): $1017-$ 22.

12. Pahwa S, Shailja G, Jasmine K. Thyroid dysfunction in dysfunctional uterine bleeding. J Adv Res Bio Sci 2013;5(1):78-83.

13. Padmaleela K, Thomas V, Lavanya KM, et al. Thyroid disorders in dysfunctional uterine bleeding (DUB) among reproductive age group women- a cross-sectional study in a tertiary care hospital in Andhra Pradesh India. Int J Med Pharma Sci 2013;4(1):41-6.

14. Kaur T, Aseeja V, Sharma S. Thyroid dysfunction in dysfunctional uterine bleeding. Web Med Central Obstet Gynaecol 2011;2(9):1-7.

15. Gowri M, Radhika BH, Harshini V, et al. Role of thyroid function tests in women with abnormal uterine bleeding. Int J Reprod Contracept Obstet Gynecol 2014;3(1):54-7.

16. Sangeeta AN, Vinita S, Namrata Y, et al. Role of thyroid dysfunction in patient with menstrual disorders in tertiary centre of walled city of Delhi. The journal of obst and gynaecol of India 2016;66(2):115-9. 